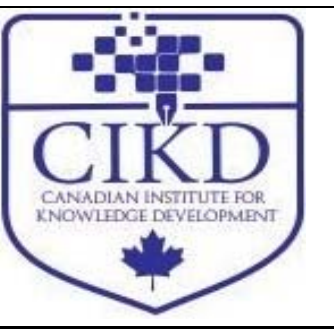

\title{
Prediction of Selected Personality Characteristics of Businessmen in the Context of their Potential to Work with Customer
}

\author{
Tatiana Lorincová $^{1 *}$, Anna Tomková ${ }^{2}$ Ladislav Suhányi ${ }^{3}$ \\ ${ }^{1}$ Prešov University in Prešov, Faculty of Management, Department of Managerial Psychology \\ ${ }^{2}$ Prešov University in Prešov, Faculty of Management, Department of Managerial Psychology \\ ${ }^{3}$ Prešov University in Prešov, Faculty of Management, Department of Marketing and International Trade
}

\begin{tabular}{|c|c|}
\hline & ABSTRACT \\
\hline \multicolumn{2}{|l|}{ Keywords: } \\
\hline $\begin{array}{l}\text { Personality } \\
\text { Characteristics, } \\
\text { Businessmen, Work with } \\
\text { Customer }\end{array}$ & $\begin{array}{l}\text { The current paper aimed to analyze the predictive power of conscientiousness and } \\
\text { agreeableness which are important personality characteristics of businessmen and related to } \\
\text { potential to work with customers. The sample consisted of } 122 \text { respondents, } 42 \text { women and } \\
80 \text { men (average age was } 28.71 \text { and standard deviation } 2.98 \text { ) working in business area with }\end{array}$ \\
\hline $\begin{array}{l}\text { Received } \\
20 \text { October } 2017\end{array}$ & the level of agreeableness and conscientiousness developed by McCrae and Costa (1987) in \\
\hline $\begin{array}{l}\text { Received in revised form } \\
21 \text { May } 2018\end{array}$ & $\begin{array}{l}\text { Slovak translated by Hřebičková and Urbánek (2001) and SKASUK- Scale of potential to } \\
\text { work with customer developed by Sonnenberg in Slovak translated by Kováč (2006). Based } \\
\text { on the confirmed aspects it was concluded that motivation to help had significant predictive }\end{array}$ \\
\hline $\begin{array}{l}\text { Accepted } \\
26 \text { May } 2018\end{array}$ & $\begin{array}{l}\text { power in predicting conscientiousness. Dominance and social appreciation did not have } \\
\text { significant predictive power in predicting conscientiousness. We found that characteristics }\end{array}$ \\
\hline $\begin{array}{l}\text { Correspondence: } \\
\text { tatiana.lorincova@unipo.sk }\end{array}$ & $\begin{array}{l}\text { which are potential to work with customer did not have significant predictive power in } \\
\text { predicting agreeableness. Social appreciation contributed to prediction of agreeableness at } \\
\text { significant level. }\end{array}$ \\
\hline
\end{tabular}

People have been the most valuable resource of organizations but this view is often ignored. However, organizations are beginning to realize that their future depends on people and not on the size of buildings, equipment and land. Intellectual capital of organizations is covered 
through particular employees. Employees of organization have different personalities that are influenced by many different qualities. We focused on potential to work with customer from a view of personalities of the tradesmen, who apart from their professional abilities, also have certain qualities that are necessary for doing good business work and communicating with other people.

\section{The Literature Review}

Conscientiousness and agreeableness are considered personality traits, which are important part in Big Five construct. Agreeableness is explained as good-natured, trustful, and cooperative feature. Conscientiousness is characterized by being responsible, orderly, and dependable (John \& Srivastava, 1999). Neuroticism is characterized by being easily upset and emotionally unstable. Openness is characterized by being intellectual, polished and independent-minded. Finally, extraversion is characterized as being talkative and assertive (Barlett, Anderson, 2012).

Conscientiousness as the Big Five construct is described in three related facets (Judge et al., 1999): achievement orientation (hardworking and persistent), dependability (responsible and careful), and orderliness (orderly and organized). Costa, McCrae and Dye (1991) argue that conscientiousness is related to an individual's degree of self-control, as well as a need for achievement, order and persistence. It is considered a valid predictor of success at work.

Agreeableness is a personality trait and agreeable persons are cooperative (trusting of others and caring) as well as likeable (good-natured, cheerful and gentle). It is possible that this trait is related to career success. For example, the flexibility, creativity and intellectual orientation of open individuals may be features to succeed in many occupations (Judge et al., 1999).

How to work with customers is important in many scientific research. Theorists still emphasize on firm performance and customer value as well as the dual creation of firm and customer value (Payne \& Frow, 2005). One of the original big ideas in marketing is that in order for firms to succeed, they should not focus on selling products but rather on fulfilling needs (Levitt, 1960). A drill manufacturer is in the business of providing a customer a hole, and a railroad company is in the business of providing transportation (Boulding, Staelin, Ehret, \& Johnston, 2005).

Today, other marketing scholars have focused on the core capabilities of the firms in order to develop and maintain good customer relationships. In some sense, this was a formalization of the concept and processes implied by the "three Cs" (i.e., customer, company, and competitor) analysis. As a result, concepts such as market orientation, market focus (Day, 1994), and market-based learning were developed that emphasized the establishment of good information processes and capabilities within the firm to understand the needs and wants of customers, thus making firms more efficient and effective in managing customer relationships. In addition, there was an evolution from product, or brand management to customer management (Sheth, 2005).

\section{Method}

The main goal of the research is to analyze selected personality traits through verification of predictive power characteristics which are related to potential to work with customer. 
$\mathbf{H}_{1}$ : We assume that frustration tolerance, achievement motivation, motivation to help and empathy contribute to the prediction of conscientiousness at significant level.

$\mathbf{H}_{2}$ : We assume that dominance and social appreciation do not contribute to the prediction of conscientiousness at significant level.

$\mathbf{H}_{3}$ : We assume that frustration tolerance, motivation to help, and empathy contribute to the prediction of agreeableness at significant level.

$\mathbf{H}_{4}$ : Dominance, achievement motivation and social appreciation do not contribute to the prediction of agreeableness at significant level.

\section{Participants}

Research sample consisted of 122 respondents aged from 24 to 51 years (average age was 34.74 with standard deviation 5.76). The proportionality of gender was uneven; the sample contained 80 men and 42 women. The research sample consisted of 62 Slovak and 60 Ukrainian respondents living in city (70 respondents) and countryside (52 respondents) and working in business area with customers.

\section{Materials}

We used two self- reported questionnaires, which measure selected personality traits (Extraversion, Agreeableness, Conscientiousness, Neuroticism, and Openness to Experience) and potential to work with customer.

NEO- Five Factor Inventory. The Five Factor Inventory is well known methodology, which measures personality traits (the level of Extraversion, Agreeableness, Conscientiousness, Neuroticism, and Openness to Experience) developed by McCrae \& Costa (1987) in Slovak and translated by Hřebičková and Urbánek (2001). The Five Factor Inventory contains 34 items, which are 5- point's scale (1- strongly disagreement to 5- strongly agreement). The Five Factor Inventory consists of 5 personality factors or traits: Extraversion is characterized by excitability, sociability, talkativeness, assertiveness and high amounts of emotional expressiveness. Agreeableness which includes attributes such as trust, altruism, kindness, affection and other prosocial behaviors. People who are high in agreeableness tend to be more cooperative while those low in this trait tend to be more competitive and even manipulative. Conscientiousness that includes high levels of thoughtfulness with good impulse control and goal-directed behaviors. Those who are high on conscientiousness tend to be organized and mindful of details. Neuroticism is a trait characterized by sadness, moodiness, and emotional instability. Individuals who are high in this trait tend to experience mood swings, anxiety, moodiness, irritability and sadness. Those who are low in this trait tend to be more stable and emotionally resilient. Openness to Experience includes characteristics such as imagination and insight. Those who are high in this trait also tend to have a broad range of interests. People who are high in this trait tend to be more adventurous and creative. People who are low in this trait are often much more traditional and may struggle with abstract thinking (McCrae \& Terracciano, 2005).

SKASUK- Scale of potential to work with customer. We used standardized questionnaire which is called Scale of potential to work with customer (SKASUK) developed by Sonnenberg and translated by Kováč (2006). The SKASUK questionnaire contains 94 statements and it consists 
of four motivational and four compensatory scales. The individual entries are rated with number $1=$ agree with statement and number $0=$ disagree with statement. Motivational scales consist of four motives as social appreciation that contains social motive, motivation to help that contains motive to be at the service, achievement motivation that contains motive of performance, and dominance that contains motive of power.

Compensatory scales consist of four scales as extraversion that contains the ability to access other people, frustration tolerance that contains the ability not to be discouraged by failure, empathy that contains the ability to be able to feel empowered by others, and self- observation that contains the observation and analysis of own behavior.

\section{Results}

The objective of the research was to analyze conscientiousness and agreeableness through verification of predictive power of selected characteristics related to work with customer (Frustration tolerance, Achievement motivation, Motivation to help, Empathy, Social appreciation and Dominance).

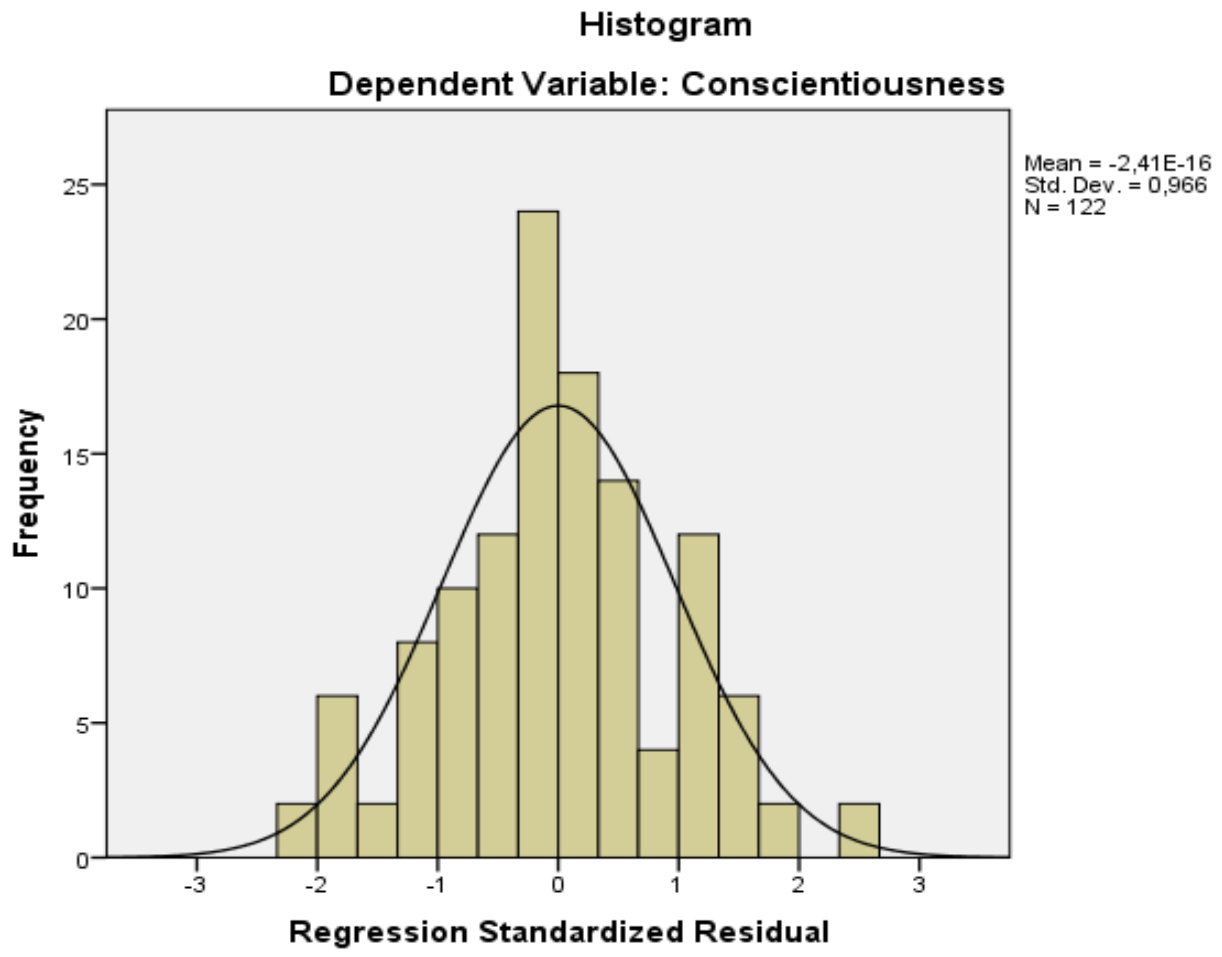

Figure 1. Graphical display of regression standardized residual with dependent variable: conscientiousness

The results were analyzed by using SPSS 20 and assessed by regression analysis. The histogram shows possibility for using linear regression because of the normality of collocation of regression standardized residual. Table 1 shows predictive power of independent variables. 
Table 1

Prediction of Conscientiousness through Selected Characteristics Related to Work with Customer

\begin{tabular}{llllcc}
\hline Predictors of conscientiousness & $\mathrm{B}$ & SD Error & $\beta$ & $\mathrm{t}$ & $\mathrm{p}$ \\
\hline Frustration tolerance & .16 & .46 & .037 & .36 & .72 \\
Achievement motivation & .04 & .31 & -.01 & -.134 & .89 \\
Motivation to help & .73 & .33 & .24 & 2.22 & .02 \\
Empathy & -.24 & .28 & .28 & -.86 & .38 \\
Social appreciation & .37 & .28 & .12 & 1.31 & .19 \\
Dominance & -.49 & .29 & -.17 & -1.69 & .09 \\
\hline
\end{tabular}

The results showed predictive power of motivation to help to conscientiousness. Examined construct explained $13 \%$ of prediction with $\mathrm{R}^{2}=.13$. Motivation to help had significant predictive power, $\beta=.24, \mathrm{p}<.05$. Hypothesis 1 was not confirmed because frustration tolerance, achievement motivation and empathy did not dispose with significant predictive power to conscientiousness.

We assumed that dominance and social appreciation do not contribute to prediction of conscientiousness at significant level. Hypothesis 2 was confirmed, because dominance and social appreciation did not contribute with a significant power to the explanation of conscientiousness (social appreciation: $\beta=.12, p=.191$ and dominance: $\beta=-.17, p=.092$ ).

\section{Histogram}

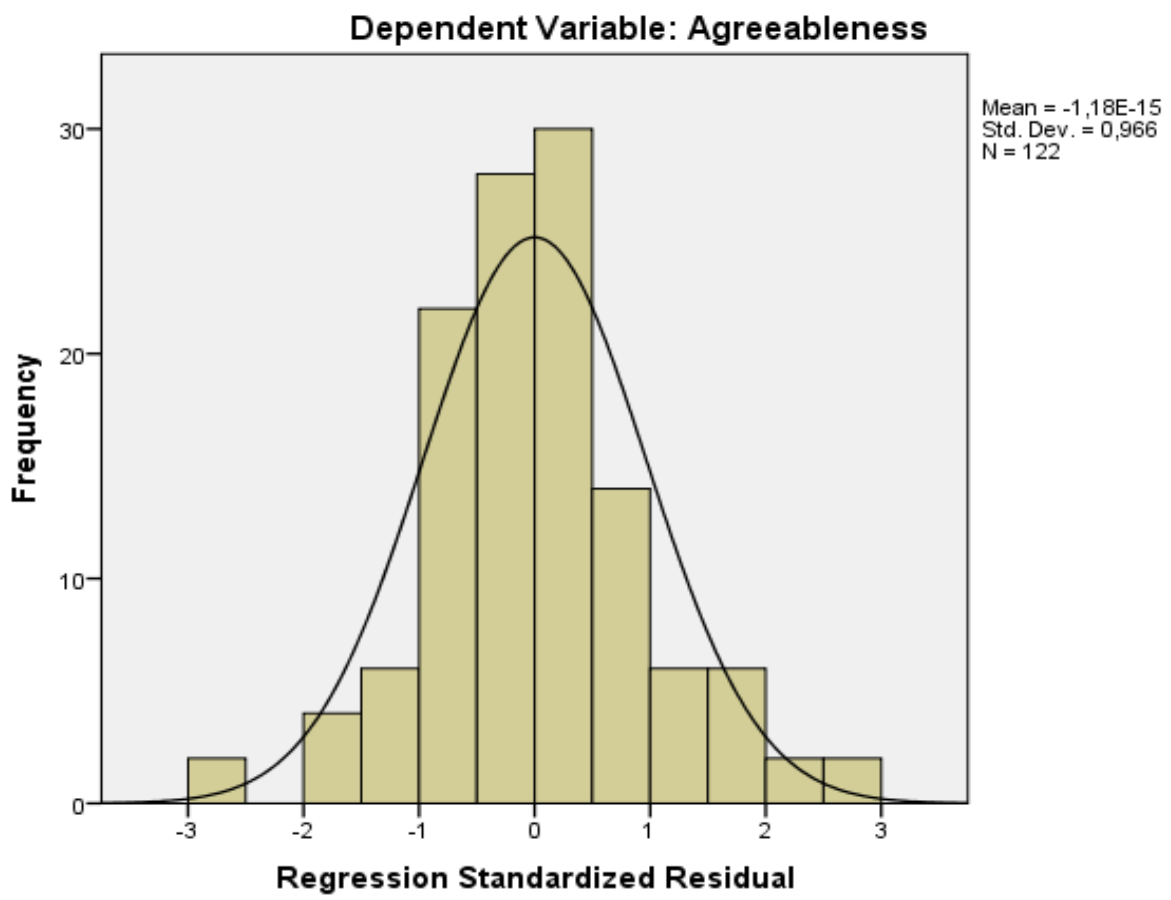

Figure 2. Graphical display of regression standardized residual with dependent variable: agreeableness

The histogram shows possibility for using linear regression because of the normality of collocation of regression standardized residual. Table 2 shows predictive power of independent variables. 
Table 2

Prediction of agreeableness through selected characteristics related to work with customer

\begin{tabular}{lccccc}
\hline Predictors of agreeableness & $\mathrm{B}$ & $\mathrm{SD}$ Error & $\beta$ & $\mathrm{t}$ & $\mathrm{p}$ \\
\hline Frustration tolerance & -.20 & .41 & -.04 & -.48 & .62 \\
Achievement motivation & .20 & .28 & .28 & .72 & .47 \\
Motivation to help & .24 & .30 & .30 & .80 & .42 \\
Empathy & -.14 & .25 & .25 & -.57 & .57 \\
Social appreciation & .72 & .25 & .25 & 2.83 & .005 \\
Dominance & -.14 & .26 & .26 & -.54 & .58 \\
\hline
\end{tabular}

The results indicated predictive power of social appreciation to agreeableness. Examined construct explained $13 \%$ of prediction, $\mathrm{R}^{2}=.13$. Social appreciation had significant predictive power, $\beta=.25, \mathrm{p}<.05$. Hypothesis 1 was not confirmed because frustration tolerance, motivation to help and empathy did not dispose with significant predictive power to agreeableness.

Hypothesis 2 was not confirmed, because social appreciation contribute with significant power to explanation of agreeableness. We assumed that dominance does not contribute to prediction of agreeableness at significant level.

\section{Discussion and Conclusion}

In this chapter we will interpret the influence of characteristics which are related to potential to work with customer regarding conscientiousness and agreeableness. We did not assume hypothesis 1 because only one characteristic, motivation to help, had significant predictive power for explanation of conscientiousness. The influence of motivation to help is explained through a link between conscientiousness and extrinsic career and life success, which are strongly related to achievement orientation of peoples' conscientious (Barrick \& Mount, 1991). Conscientious people are motivated through extrinsic motivation; whereas, motivation to help is the opposite of extrinsic motivation. It means that motivation to help is characterized through intrinsic motivation. Our results are inconsistent with previous research conducted by Barrick and Mount (1991).

On the other hand, conscientiousness seems to enable people to obtain promotions into more complex and prestigious jobs (Judge et al., 1999). It means that people with high level of conscientiousness are probably ambitious and these findings contradict the results of the present study. The results showed that motivation to help predicted conscientiousness at significant level. It means that motivation to help other people plays an important part in in this personality trait.

We also found that social appreciation contributed with significant power to the explanation of agreeableness. This finding is not very surprising in the context of cooperative nature of agreeable individuals. Similarly, the cooperative nature of agreeable individuals may lead to more successful careers, particularly in occupations where teamwork or customer service is relevant (Judge et al., 1999). The social appreciation contains social motive and the agreeableness includes attributes such as trust, altruism, kindness, affection and other prosocial behaviors. People who are high in agreeableness tend to be more cooperative while those who 
are low in this trait tend to be more competitive and even manipulative. It means that our results are in line with previous research conducted by McCrae and Terracciano (2005).

Some limitations should be addressed. First, the selected personality traits (conscientiousness and agreeableness) were measured by self-reported questionnaires. The research identified many helpful attributes for the evaluation of personality traits in relation to potential to work with customer. Overall, this study can contribute to the improvement of skills, which are necessary for working with customers.

\section{References}

Barlett, C. P., \& Anderson, C. A. (2012). Direct and indirect relations between the Big 5 personality traits and aggressive and violent behavior. Personality and Individual Differences, 52, 870-875.

Barrick, M. R., \& Mount, M. K. (1991). The Big Five personality dimensions and job performance: A meta- analysis. Personnel Psychology, 44, 1-26.

Boulding, W., Staelin, R., Ehret, M. \& Johnston, J. W. (2005). A customer relationship management roadmap: what is known, potential pitfalls, and where to go. Journal of Marketing, 69, 155-166.

Costa, P. T. J., \& McCrae, R. R., \& Dye, D. A. (1991). Facet scales for agreeableness and conscientiousness. A revision of the NEO Personality Inventory. Personality and Individual Differences, 2, 887-898.

Day, G. S. (1994). The capabilities of market-driven organizations. Journal of Marketing, 58, 37-52.

Hřebičková, M., \& Urbánek, T. (2001). NEO pětifaktorový osobnostní inventář. Praha: Testcentrum.

John, O. P., \& Srivastava, S. (1999). The Big-Five trait taxonomy: History, measurement, and theoretical perspectives. In L. Pervin, \& O. P. John (Eds.), Handbook of Personality: Theory and Research, (pp. 102-138) New York: Guilford Press.

Judge, A. T., Higgins, A. C., Thoresen, J. C., \& Barrick, M. R. (1999). The Big Five personality traits, general mental ability, and career success across the life span. Personnel Psychology, 52, 621-652.

Kováč, J. (2006). How to embrace e-business and make it succeed? Destination CRM, Retrieved from www.destinationcrm.com

Levitt, T. (1960). Marketing myopia. Harvard Business Review, 38, 45-60.

McCrae, R. R., \& Costa, P. T. (1987). Validation of the five-factor model of personality across instruments and observers. Journal of Personality \& Social Psychology, 52, 81-90.

McCrae, R. R., \&Terracciano, A. (2005). Universal features of personality traits from the observer's perspective: Data from 50 different cultures. Journal of Personality \& Social Psychology, 88, 547-561.

Payne, A, \& Frow, P. (2005). A strategic framework for customer relationship management. Journal of Marketing, 69, 16776.

Sheth, J., (2005). The benefits and challenges of shifting strategies. Customer Management, 4-5.

Vorhies, D. W., \& Morgan, N. A. (2005). Benchmarking marketing capabilities for sustainable competitive advantage. Journal of Marketing, 69, 80-94. 